\title{
Laparoscopic cholecystectomy: are we being safe?
}

\author{
Chandika Liyanage, MPhil MS MRCS (Eng.) \\ Specialist Hepatobiliary Pancreatic and Gastrointestinal Surgeon and, Senior Lecturer in Surgery, Division of Hepatobiliary \\ Surgery and Liver transplant Surgery, Department of Surgery, University of Kelaniya Medical School, Sri Lanka.
}

\begin{abstract}
Laparoscopic cholecystectomy (LC) is the gold standard for the treatment of symptomatic cholelithiasis [1]. Though surgeons in Sri Lanka were careful to embrace the laparoscopic approach, the operation is now widely practiced across the country. Therefore it would be natural to encounter more complications of this procedure compared with previous times.
\end{abstract}

Nevertheless, it is important for surgeons who embark on this procedure to have an understanding of the complications of laparoscopic cholecystectomy and the appropriate pathways of management. Though complications are inevitable in surgery, surgeons have a moral and social obligation to maintain complications within an acceptable range - scrutiny is therefore essential in surgical practice. Currently in Sri Lanka, the only way of scrutiny is by institutional morbidity and mortality meetings. The intention of this article is to enlighten surgeons of some facts that may influence practice in order to avoid complications and other difficulties when performing LC, not to bring forth the shortfalls of our system.

The acceptable incidence of bile duct injury(BDI) at laparoscopic cholecystectomy is less than $0.4 \%$ [2].Over time, this incidence has reduced and has stabilised at between 0.2 and $0.4 \%$. Vascular injuries during LC are encountered almost exclusively in the context of bile duct injury. The rate of concomitant vascular injury is in the region of 7 to $32 \%$ [3.4].There are widespread notions that the laparoscopic approach has a higher incidence of bile duct injury compared to open cholecystectomy. In fact, the incidence of BDI in open cholecystectomy has been on the rise in the era of laparoscopic surgery.This may be because open cholecystectomy is now performed for complicated gall bladder disease or after a failed laparoscopic approach. Therefore, it is difficult to compare the incidence of BDI in laparoscopic versus open cholecystectomy

Correspondence: Chandika Liyanage, Specialist Hepatobiliary Pancreatic and Gastrointestinal Surgeon and, Senior Lecturer in Surgery, Division of

Hepatobiliary Surgery and Liver transplant Surgery, Department of Surgery, University of Kelaniya, Medical School, Sri Lanka.

E-mail:chandikaliyanage@hotmail.com
[5]. Based on the experience of working in five hepatobiliary units in Australasia, each performing large numbers of gall bladder operations, and with encountering biliary injuries as a surgical endoscopist, I would like to reflect on the issue of cholecystectomy and BDI.

\section{Factors contributing to bile duct injury}

Many factors may contribute to an iatrogenic BDI injury during LC. These may be patient factors, issues pertaining to instruments, and to surgeon related factors. Patient factors such as obesity, advanced age, male sex, and intraabdominal adhesions should call for extra precaution. At surgery,local factors such as severe inflammation and/or infection, aberrant anatomy, and haemorrhage set the stage for BDI. It is worthwhile to understand that laparoscopic surgery has a learning curve, and it should be mandatory that spatial dimensions of laparoscopic surgery be embedded into the minds of trainees early in their carriers. Current trainees in the surgical program, compared to surgeons who had to learn laparoscopic surgery later in their careers, will predictably be better at laparoscopic cholecystectomy by participating in structured training. HOLT is a Hands-on Laparoscopic Training course conducted by the College of Surgeons of Sri Lanka to help trainees develop basic laparoscopic skills. This course is now mandatory for trainees in the MD-Surgery programme. Thereafter, bench learning should be reinforced in the operating room by clinical trainers mentoring trainees in a stepwise structured manner. As we have previously described [6], it would be useful to mentor and train in laparoscopic cholecystectomy with focus on the salient steps of the operation, making the learning curve objective and transition to independent operating smooth. Most injuries occur within a surgeon's first one hundred operations, and a third happens after the surgeon has completed over 200 [7,8], suggesting that there is more to complications than sheer inexperience.

\section{Causes}

Error analyses in large series of patients who have had bile duct injury have shown that mis-identification of the common bile duct, the common hepatic duct, or an aberrant duct (usually on the right side) is the most common cause of bile duct injury. 
An error of perception is likely the cause rather than deficient knowledge, decision-making, or the technical skill of the surgeon [9]. Perceptual error, not necessarily duct injury, usually occurs early in the course of surgery, at the stage of initial anatomical orientation or preliminary dissection [10]. The operation is then completed, based on errant land marks, paving the way for BDI. In addition, technical failures like slippage of a clip over the cystic duct stump, improper placement of a clip, inadvertent diathermy injury, and disruption of cholecysto-hepatic connections at the liver bed could result in a variety of bile duct injuries albeit less catastrophic.

\section{Avoiding bile duct injury}

Performing LC can be compared to flying an airplane; at the outset, it's in the surgeon's best interest that all the equipment is checked and s/he has an able assistant.In this regard, an assistant should not be merely an adept camera holder but one who should possess sufficient knowledge of biliary anatomy and laparoscopic cholecystectomy to help the operating surgeon cross-check during vital, and often irreversible, steps during the operation. There is consensus that careful dissection and correct interpretation of the anatomy avoids the complication of bile duct injury during cholecystectomy. Proper orientation at the start is important to avoid dissecting along the lines of disaster. It will be useful to position the gallbladder on the screen between seven and 10 o'clock and follow the line of safety. Following initial orientation, a verbal cross-check between the surgeon and assistant must be carried out before dissection is commenced, and repeated after dissection, before structures are clipped or divided. Where a difficult LC can be predicted either at the time of work -up or early into the operation, it will be wise to seek assistance of a colleague instead of a junior trainee. It has been shown that if the cystic duct and cystic artery are conclusively and correctly identified before division, more than $70 \%$ of bile duct injuries may be prevented [11].

There may be a role for abandoning the procedure right at the outset, but patients must be consented for such an event, and at most times, LC may be attempted two to three months later, thus avoiding an open procedure. In the best interest of the patient, the decision to convert to open cholecystectomy should be early in the operation, beforean error is made. As experts agree, conversion to an open cholecystectomy is never a failure of the surgeon. As Strasberg points out, the negative effects of conversion, abandoning the procedure or placing a cholecystostomytube are minor compared to the disastrous consequences of bile duct injury [12].

\section{Use of intra-operative cholangiography (IOC)}

Intra-operative cholangiography to facilitate safe laparo- scopic cholecystectomy may be under-utilised in Sri Lanka. Although there are no prospective randomised trials which have shown a decrease in the incidence of bile duct injury in association with the use of intraoperative cholangiography (IOC), a large retrospective population-based study has reported a higher incidence of BDI in patients who did not have IOC [13].

Owing to logistical difficulty with IOC as a routine undertaking, it has been recommended on a selective basis, and has several benefits in addition to delineating standard bile duct anatomy. A group from Canberra, which performed IOC routinely during laparoscopic cholecystectomy, demonstrated the "Gall bladder sign"during IOC with the cystic duct clamped, which suggested the presence of cholecysto- hepatic connections. They were able to avoid bile leaks from unsuspected connections from the gall bladder bed [14]. An IOC requires the surgeon to acquire additional skills in performance of safe LC. Also, it should be performed on a regular basis to ensure unhindered IOC during a difficult LC and to keep surgical teams and operating room staff well practiced. Furthermore, to the untrained eye, interpretation of the bile duct anatomy and demonstration of a bile leak may pose additional difficulty. From a training perspective, IOC should become an essential step in structured LC protocols.

\section{Bile duct injury}

Most surgeons will encounter a BDI in a lifetime. The data have shown that over $90 \%$ of bile duct injuries are missed at the time of operation [15]. A high degree of suspicion is thus warranted in those who become unwell in the early postoperative period. During 2011-2012, the Hepatobiliary unit at North Colombo Teaching Hospital and the Gastroenterology and Hepatology unit of the National Hospital of Sri Lanka encountered approximately 15 bile duct injuries referred for endoscopic retrograde choledocho-pancreatographyand repair [author, unpublished data]. Of these,4 were Strasburg Type E complete transections.Based on the knowledge that other tertiary referral units with a specialized hepato-biliary interest exist in Sri Lanka, this figure is likely an under-estimation of the actual incidence of BDI following LC in the country.

The management of bile duct injuries can be categorized as non-operative versus operative and early versus delayed repairs. The method and timing of the repair will depend on the timing of the injury and the experience of the surgeon and the patient's clinical status. Immediate or early repair ( $<1$ week) is favoured when the complete extent of the injury is understood, without a major vascular injury, and when there is no sepsis. Despite the excellent functional and anatomical results that can be achieved by early referral and appropriate early management, the quality of life 


\section{Laparoscopic cholecystectomy: are we being safe?}

following BDI might be unsatisfactory [15]. This is mainly because of repeated interventions that may be needed in some patients, especially if there are ischaemic strictures of the extra hepatic biliary tree. Such patients have shown a greater tendency to seek legal counsel.

As previously mentioned, if LC is analogous to flying an aircraft, a video-record of the operation will be its "black box". A video record of LC is an invaluable learning and reflective tool. The down-side of video-records is that, like in all airline crash investigations, investigators will want to review a record in the event of an enquiry.

\section{References}

1. Liyanage CAH, Sadakari Y, Kitada H, Ienaga J, Tanabe R, Takahata S, Nabae T, Tanaka M. Prevention of iatrogenic bile duct injuries in difficult laparoscopic cholecystectomies: is the naso-biliary drain the answer?J HepatobiliaryPancreat Surg. 2009; 16(4): 458-62.

2 .Eikermann M, Siegel R, Broeders I, Dziri C, Fingerhut A, Gutt C, Jaschinski T, Nassar A, Paganini AM, Pieper D, Targarona E, Schrewe M, Shamiyeh A, Strik M, Neugebauer EA. : Prevention and treatment of bile duct injuries during laparoscopic cholecystectomy: the clinical practice guidelines of the European Association for Endoscopic Surgery (EAES). SurgEndosc. 2012; 26(11): 3003-39.

3. Halasz N. Cholecystectomy and hepatic artery injuries. Arch Surg 1991; 126(2): 137-8.

4. Deziel D, Millikan K, Economou S, et al. Complications of laparoscopic cholecys- tectomy: a national survey of 4,292 hospitals and an analysis of 77,604 cases. AmJ Surg 1993; 165(1): 9-14.

5. Karvonen J, Salminen P, Grönroos JM ; Bile duct injuries during open and laparoscopic cholecystectomy in the laparoscopic era: alarming trends. SurgEndosc. 2011; 25(9): 2906-10.

6. Liyanage CAH, Sabaratnam VY, Deen KI. A struc- tured training programme in laparoscopic cholecystectomy. Ceylon Med J. 2006; 51(2): 74-5.

7. Archer SB, Brown DW, Smith CD, Branum GD, Hunter JG. Bile duct injury during laparoscopic cholecystectomy: results of a national survey. Ann Surg 2001; 234: 549-59.

8. Francoeur JR, Wiseman K, Buczkowski AK, Chung SW, Scudamore CH. Surgeons' anonymous response after bileduct injury during cholecystectomy. Am J Surg 2003; 185: 468-75.

9. Cl. Bertrand: Prevalence of Bile Duct Injury Following Cholecystectomy:ActaChirBelg, 2003; 103: 143-50.

10. Diamond T, MoleDJ : Anatomical orientation and cross-checking-the key to safer laparoscopic cholecystectomy: BJS 2005; 92: 663-64

11. Strasberg S. Error traps and vasculo-biliary injury in laparoscopic and open cholecystectomy. J HepatobiliaryPancreatSurg 2008; 15(3): 284-92.

12. Strasburg SM, Hertl M, Soper NJ. An analysis of the problem of biliary injury during laparoscopic cholecystectomy. J Am CollSurg 1995; 180: 101-25

13. Waage A, Nilsson M. Iatrogenic bile duct injury: a population-based study of 152,776 cholecystectomies in the Swedish Inpatient Registry. Arch Surg 2006; 141: 1207-13.

14. Liyanage CAH, Ganandha S, Mosse C, "Gall bladder sign" on intraoperative cholangiogram as an indicator of aberrant anatomy at the gallbladder bed: an important warning sign. Scientific sessions of the International Hepatobiliary Association Biennial meeting. Buenos Aries, Argentina 2010.

15. Melton GB, Lillemoe KD, Cameron JL, Sauter PA, Coleman J, Yeo CJ. Major bile duct injuries associated with laparoscopic cholecystectomy: effect of surgical repair on quality of life. Ann Surg 2002; 235: 888 -95. 